\title{
CORRESPONDENCE
}

\author{
Are consultants accountable? \\ P Kennedy, FRCPSYCH....................... 1566 \\ What is a good GP? \\ J B O'Donovan, MRCGP; N Higson, BM; A P \\ Joseph, MRCGP. \\ Procedures for obtaining informed consent \\ R R H Lovell, FRCP; R H Nicholson, BM; \\ R J Simes, FRACP, and M H N Tattersall, \\ FRACP ................................... 1567 \\ Time to scrap creatinine clearance? \\ R Gabriel, FRCP ......................... 1568 \\ Effects of breast conservation on psychological \\ morbidity \\ PC Milner, MRCP, and J P Nicholl, MSC ....... 1568 \\ Respiratory symptoms and bronchial reactivity
}

J B L Howell, FRCP, and W E Waters, FFCM ... 1568

\begin{abstract}
Whooping cough immunisation for children with cerebral irritation or damage in the neonatal period

D Elliman, MRCP
\end{abstract}

Confusion after admission to hospital in elderly patients using benzodiazepines Charlotte E Daman Willems, MRCP, and M J

Dillon, FRCP ................................ 1569

Relapse of duodenal ulcer

R McCloy, FRCS; J P Miller, FRCP; B J Salena, FRCPC, and R H Hunt, FRCP

Randomised trial of treatment of hypertension in elderly patients in primary care

M McCarthy, MFCM .

Because we receive many more letters than we have room to publish we may shorten those that we do publish to allow readers as wide a selection as possible. In particular, when we receive several letters on the same topic we reserve the right to abridge individual letters. Our usual policy is to reserve our correspondence columns for letters commenting on issues discussed recently (within six weeks) in the BMF.

Letters critical of a paper may be sent to the authors of the paper so that their reply may appear in the same issue. We may also forward letters that we decide not to publish to the authors of the paper on which they comment.

Letters should not exceed 400 words and should be typed double spaced and signed by all authors, who should include their main degree.

\section{Are consultants accountable?}

SIR,-Dr Anne Grüneberg writes (1 November, $p$ $1175)$ that consultants are accountable to their patients, the regional health authority, and their peers. BMA News Review (November, p 12) insists, "Doctors are clinically responsible to no one but the General Medical Council." I've said these things myself, but now I wonder.

Can one really be accountable to patients, who have the power to act only as individuals through the complaints procedure about particular incidents, which have to be pretty serious and well proved if there is to be any noticeable sanction on the doctor? Many have not the courage to complain, and none is in any position to make an overall appraisal of a doctor's performance.

And is it realistic to think of doctors being accountable to a regional health authority whose members and officers may never see a consultant throughout his entire career? Large organisations that hold contracts at head office do not expect accountability to lie there but delegate the responsibility to people who can see what is going on. Peer review or medical audit is uncommon and always optional.

And surely accountability to the General Medical Council is an aspiration for very low standards, where there are sanctions for only gross misconduct, negligence, or criminal behaviour.

Within the normal meaning of the word, therefore, consultants are accountable to no one.

Accountability, of course, is not just about imposing sanctions for poor performance. It is about identifying problems early and helping to resolve them. It is about ensuring that action is taken to alter work responsibilities if someone is failing to cope. In conversations with consultants one hears concern expressed that no one takes responsibility for helping a colleague who isn't coping. Thus there are consultants whom people gossip about, complain about, and who, through eccentricity or just aging, have declining caseloads and credibility. It is damaging for the individuals concerned and for the profession. That there has developed in recent years an increasingly elaborate and secret system of checking on sick doctors who are close to clinical catastrophe is not reassuring but symptomatic of an unresolved problem.

Dr Grüneberg mentioned that consultants who look after budgets may have some limited accountability to general managers. But whether or not consultants hold budgets general managers have potential for powerful sanctions, because they control all resources, and one has heard stories of doctors being stripped of junior staff, beds, and so on when their performance has been so bad that even their medical colleagues condone tough managerial action. But it is a degrading process for manager and doctor when the manager can only impose sanctions without also being able to guide

\section{What is a good GP?}

SIR,-I read Ms Susan Holmes's article (29 November, p 1411) with a sense of mounting anger. Perhaps she was just trying to provoke doctors like me. I think not; I would not wish to accuse her of bad taste. Her view of the pastgeneral practice before 1948 and in the early days of the NHS-is rose coloured and naive. It is not unlike one's recollection of childhood summers. I did not practise medicine then. However, my older patients and elderly friends and relatives have different recollections. They never saw a doctor in their homes as children. Unless you were "on the panel" a doctor's visit was a rare luxury. and help, which is what makes the accountability process healthy.

I note that the Central Committee for Hospital Medical Services is considering setting up a professional panel to deal with consultants who are said to be falling far short of contractual obligations. It sounds too remote, impersonal, and formal to convey any of the usual benefits of a personal accountability process and can address only very minimum standards.

Managers appraise managers, nurses appraise nurses. I wonder if consultants should be exploring the feasibility of a personal accountability system as the general public becomes increasingly aware that doctors, like other human beings, need their work performance monitoring. Those who have had individual appraisal throughout their careers say it is more encouraging than critical.

Bootham Park, York

Peter Kennedy

Anyway it was acknowledged that most mothers, helped by grandparents and aunts, coped with most illness. If the doctor appeared it was pretty serious.

I was a doctor such as Ms Holmes describes in the mid-1950s and 1960s, the "exclusive property" of not one but hundreds of families-always at their beck and call, day or night. I also remember what it was like in the winter after a week of heavy days and nights of interrupted sleep. My patients could always see me, my family certainly could not. My children recollect a childhood with an absent doctor father. 
There are uncaring doctors who do not listen and "dragons" at reception's gate. But many doctors and their staffs worry about the service they provide for the patients. It must be said there are also selfish, dependent, and demanding patients who produce workloads out of all proportion to their numbers. We need competent, as well as caring, doctors. Such clinical competence and good organisation geared to health promotion and the early detection of serious illness are very important to most of us. If my abdominal pain reflects my emotional pain I need a caring doctor. If the pain is the early sign of a cancer of the colon I need a competent doctor. We need "competent" patients-patients who care about their health and are willing to take some responsibility for its maintenance.

Yes, we do expect too much of our doctors. We often get more than some of us deserve. In conclusion, may I suggest that Ms Holmes should spend a week working in reception and stay with a doctor's family. My sense of anger will be a pale imitation of the outrage and anger many doctors' families will feel when they read this article.

J B O'Donovan

Itchenor,

West Sussex PO20 7DA

SIR,-Dr S G P Webster (22 November, p 1351) ends his article by discussing further qualifications which the keen GP might possess and on which he proposes the payment of a "good practice allowance" might be based. As ever, this indicates a very singleminded view of how the GP might pass his time.

Is Dr Webster aware that, although elderly patients might require increasing services from the GP, even in my south coast practice I have $57 \%$ of my personal list made up of patients too young for that category of care? I would expect that if Dr Webster's proposals for good general practice were extended to cover a typical list then, apart from having the diploma in geriatric medicine that he proposes as a measure of ability, I would need to possess 47 other diplomas and certificates available in the UK and Ireland, ranging from a certificate in advanced dermatological diagnosis to a diploma in venereology.

With a typical general practice consultation of 10 minutes per patient, during the passage of which the patient might talk for half the time, the GP is allowed about eight hours' direct consultation time per patient over a general practice working life, this time being available in short bursts. How much time will be available if the GP must first acquire all the diplomas?

May I suggest that future contributors to this series make some effort to consider that the GP covers a wide range of specialties, which may all be presented within a very short space of time.

Nigel Higson

Hove, East Sussex BN3 3DX

SIR,-It is always instructive to learn the opinions of others on the quality of work you do, and a self critical attitude can sometimes be beneficially reinforced by external assessment.

I cannot claim to match up to all of Dr S G P Webster's suggested "useful markers" indicating quality of care provided, but I hope not to need much more inducement than I am already receiving to try to offer my elderly patients as adequate a service as I can. Unfortunately, the GP cannot operate effectively without back up and commit- ment from colleagues and others "in the team," as Dr Webster readily agrees. This back up must come at least as much from specialist geriatricians. I quote from a letter I had written to a consultant geriatrician only the day before Dr Webster's article landed on my doorstep.

"Dear

$$
\operatorname{Re}:
$$

Thank you for admitting the above patient and I am very grateful for your help in dealing with the problem. I regret too that, under provocation, I 'lost my cool' with you in the recent telephone cal to discuss her potential admission. I can indeed sympathise with you in being worried about patients with dementia (or other superadded psychological disturbances) disrupting the care of others whose condition is predominantly organic and whose behaviour is therefore 'ward acceptable.'

However, consider if you will the predicament of the primary care doctor who has been attempting, vainly, to obtain a more satisfactory pattern of care for just such a situation as exemplified by this patient. She has been causing increasing concern to me for several years with a background of cultural isolation and increasing mild dementia, punctuated by toxic confusional episodes during any one of which the precarious balance of domestic care becomes 'tipped over' into an impossible management. Every time one of these episodes clears I have spent much time with the relations trying to persuade them to rationalise the management and pre-empt such problems; for reasons of their own they have declined this advice and we therefore lurch from crisis to crisis and live poised for the next disaster. It is very unsatisfactory, but when another confusional episode arises there is no choice than, without delay, to obtain a placing for her somewhere. It is also, regrettably, not possible usually to detect clinically whether it is a respiratory problem, a cardiac, a urinary, or some combination of all or any of these to explain an individually worse episode. In such circumstances the patient has to be 'sorted out' somewhere before the appropriate 'pigeon hole' is located. At this point nobody ever wants to know.

The general medical team say the patient is too old, your outfit agonises over the psyche, and the psychiatrists want organic pathology diminished first!

Meanwhile, the relatives and attendants mutiny over further home care-I cannot blame them; she is by then too difficult to contain, and the general practitioner has to place her somewhere.

I visit quite regularly and have regular contact with her family. I have also attended her 'out of hours' several times and it is intolerable in these circumstances to be told-or have it implied-that the patient has received no adequate assessment, inappropriate demands to the wrong people are being made, etc, etc.

I knew in advance from previous episodes the type of situation I would find in the home when I arrived. I was attempting to obtain the desperate placemen required before too late in the day-which we are told is preferred for hospital admissions generally - and it is simply inviting general practitioners faced with such a response to abrogate all responsibility and simply summon an ambulance and say 'Dump in casualty.' I do not think either the patient's best interest or, indeed, any attempt at rational use of scarce hospital resources, is likely to be achieved in this manner. However, that is likely to be the effect of such a policy if a more helpful approach when a desperate situation is faced cannot be worked out between the various hospital admitting teams and the referring primary care doctor.

I do not expect you to have easy answers - there are none, I am aware-but I invite you to ponder these matters. ..."

Unfortunately, the situation epitomised by my letter is an almost daily trial to many of us in general practice, and my morale in looking after old people would be improved if my efforts at coping were rewarded not so much by more cash but by the availability of a less exhausting method of obtaining for them appropriate services.

A P JOSEPH AUTHORS' REPLY-Dr Nicholson's concerns about Smethwick,

West Midlands B66 3PZ

\section{Procedures for obtaining informed consent}

SIR,-It is good to learn of an attempt to make a critical comparison of procedures for obtaining consent in clinical trials (Dr R J Simes and others, 25 October, p 1065). Dr Simes and colleagues report that the National Health and Medical consent for studies it supports. The written guidance since 1982, in the council's statement on human experimentation, reads (in part): "Consent should be obtained in writing unless there are good reasons to the contrary. If consent is not obtained in writing, the circumstances under which it is obtained should be recorded."

One of the reasons the guideline was phrased in this way was to avoid inhibiting the sort of approach which Dr Simes and his colleagues have made-an approach which many of us might consider we should have made long ago.

R R H LOVELL Chairman

NHMRC Medical Research Ethics

Committee,

Carlton, Victoria 3053,

Australia

SIR,-Studies of the effect on patients of differing strategies for giving information and obtaining consent are important contributions to the present debate on informed consent. One might be inclined to welcome, therefore, the study carried out by Dr R J Simes and colleagues (25 October, p 1065), but their results may be invalidated by two design flaws.

They carried out a randomised trial of total disclosure versus "an individual approach" to giving information as a prelude to obtaining consent from patients who were candidates for inclusion in oncological clinical trials. What they did not do, however, was to tell the patients that they were being included in a trial of full versus partial information; nor did they ask the patients for their consent to being allocated at random either to full or partial information disclosure. The trial and the investigators would therefore seem to have had an inbuilt bias against full information disclosure, which was one of the strategies being tested.

The second flaw lies in the choice of subjects. Similar trials have examined homogeneous groups of patients, such as those about to undergo hysterectomy. In this case, however, patients were included who were candidates for 16 different clinical trials. Although the patients were stratified according to three different types of trial, the sort of information being given to different patients within one of the strata might vary widely. The stratum of trials comparing treatment with no treatment might, for instance, have included a trial of radiotherapy in primary treatment and a trial of an oral drug in prophylaxis after successful primary treatment. The anxiogenic potential of the information being given might therefore vary widely, regardless of whether full or partial information was being given.

In the absence of evidence that like was being compared with like, and in view of the inbuilt bias against one of the trial arms, it is not possible to draw any conclusions from this trial.

\section{R H NiCHOLSON}

IME Bulletin,

London WC1H 9LG

the design of our informed consent trial are invalid. We acknowledge that patients were unaware that Research Council (Australia) now requires written 